\title{
Supporting student nurses in practice with additional online communication tools
}

\author{
Dawn A. Morley
}

\begin{abstract}
Student nurses' potential isolation and difficulties of learning on placement have been well documented (Melia 1987, Thyrsoe et al 2010) and, despite attempts to make placement learning more effective, evidence indicates the continuing schism between formal learning at university and situational learning on placement (Melia 1987, Spouse 2001).
\end{abstract}

First year student nurses, entering placement for the first time, are particularly vulnerable to the vagaries of practice (Chesser-Smyth 2005). Prior to practice first year students at Bournemouth University have studied on two academic units using the medium of wikis and also demonstrate typical use of the social networking site, facebook, for their age and population (Morley 2012).

During 2012 two first year student nurse seminar groups (52 students) were voluntarily recruited for a project to determine the usage of additional online communication support mechanisms (facebook, wiki, an email group and traditional methods of support) while undertaking their first five week clinical placement. Results indicated a high level of interactivity in both peer and academic support in the use of facebook and a high level of interactivity in one wiki group. Students' qualitative comments indicate an appreciation of being able to access university and peer support whilst working individually on placement. The other modes of communication support were only used minimally. 


\section{INTRODUCTION}

The advent of Web 2.0 technologies, such as wikis and blogs and social networking sites such as Facebook, has heralded a revolutionary approach to computer users' interaction with online materials. When using these types of tools in education students no longer sit passively by their computers but are encouraged to interact with course materials and each other in order to further their understanding.

Table One: Definition of elearning terms

\begin{tabular}{|c|c|}
\hline Elearning terms & Features \\
\hline elearning & $\begin{array}{l}\text { Learning facilitated and supported } \\
\text { through the use of information and } \\
\text { communications technology }\end{array}$ \\
\hline Facebook & $\begin{array}{l}\text { A social networking website that allows } \\
\text { individuals to set up an online profile, } \\
\text { add other users as friends and exchange } \\
\text { messages. Users can post personal } \\
\text { information, upload photographs, } \\
\text { describe their interests, and link to other } \\
\text { profiles and pages. The choice to create a } \\
\text { profile in a network means that those } \\
\text { connected to that network can view that } \\
\text { profile. Users can search for friends by } \\
\text { name, Location, email and institution. }\end{array}$ \\
\hline netiquette & $\begin{array}{l}\text { The correct or acceptable way of using } \\
\text { the Internet }\end{array}$ \\
\hline $\begin{array}{l}\text { web } 2.0 \text { Tools } \\
\text { (And web } 1.0 \text { Tools) }\end{array}$ & $\begin{array}{l}\text { The second stage of development of the } \\
\text { Internet, characterized especially by the } \\
\text { change from static web pages (web 1.0) } \\
\text { to dynamic or user-generated content eg } \\
\text { wikis and the growth of social } \\
\text { networking eg Facebook }\end{array}$ \\
\hline wiki & $\begin{array}{l}\text { An editable tool for working with others } \\
\text { that has a trackable history of changes } \\
\text { (wikipedia is the most popular example). } \\
\text { Much like a blog, its strength is that can }\end{array}$ \\
\hline
\end{tabular}


be used to share multimedia resource.

Adapted from JISC websites and Oxford online Dictionary accessed 23/08/12

Co production is key to Web 2.0 tools (Grover and Stewart 2010) and knowledge is co constructed through collaborative effort (Fountain 2005, Mejias 2006). In particular Web 2.0 tools have spawned "Learning 2.0" (Grover and Stewart 2010) which builds on the traditional social constructivism view of education that learning is not solely about the individual learning in isolation but increasingly about the individual's learning being influenced as part of their group or the environment that surrounds them (Dewey 1938). This learning is particularly pertinent to practice where student nurses are being guided by more experienced colleagues in the imprecise world of professional practice (Schon 1983, Benner 1984, Levett - Jones and Lathlean 2008).

As well as promoting the co production of knowledge Web 2.0 has the potential to contribute significantly to emotional or pastoral support. Ossiansson (2010) and DeAndrea et al (2012) focus on the influence of social networking sites on social capital or the "social resources that people accrue through their relationships with others" (DeAndrea et al 2012: 16). Facebook can be influential in promoting socialisation to the college setting (DeAndrea et al 2012, Junco 2012) and, by learning through peers, students experience an increased connection and affiliation to their academic institution. A reduction in the uncertainty of a new college environment by online interaction focusing on positive and realistic expectations can assist student transition (DeAndrea et al 2012) and provide them with a valuable formative experience to start their academic careers. As Ossiansson (2010: 124) 
found, whilst working with masters students on Facebook, "a feeling of being valued, committed, seen, important and part of a group".

Although research into the use of the collaborative potential of both learning and peer support through online tools in academic institutions is increasing its potential to enhance student learning and support in practice education remains untested. From research by Melia (1987) through to the present day common problems are highlighted in the situated learning that student nurses experience in practice. Student nurses experience difficulties applying their theoretical learning to the practice setting as well as facing helplessness, dependency (Spouse 2001, Chesser-Smyth 2005) and even personal abuse (Thyrsoe et al 2010). The reliance on a mentoring support structure is seen as highly significant to the success of student learning (Myall 2008, Gray et al 2000) yet this relationship also has its difficulties. Research indicates that the mentors' clinical workload and lack of clarity of their mentoring role can have an effect on their support of students (Myall 2008, Gray et al 2000, Taylor 1997).

"Belongingness" in a clinical setting is a concept found to be influential to student nurses' situated learning (Levett -Jones and Lathlean 2008). Levett -Jones et al (2007) conclude that the third year students in their study were dependent on a sense of belonging to their practice setting in order to experience positive clinical learning. Belongingness in a clinical setting is synonymous with personal involvement in a system or environment and characteristics of being valued and socialised to the group (Levett- Jones et al 2007). This has many parallels with feelings generated by online groups and social networking sites 
(Ossiansson 2010, DeAndrea et al 2012) that have been identified as a source of social capital and motivation.

Particularly vulnerable to the vagaries of practice learning are first year student nurses who are entering practice placement for the first time "knowing a little and feeling useless" (Chesser-Smyth 2005: 323). A sense of belongingness is particular significant for first year student nurses starting out on their professional trajectory where they can be at their most vulnerable and disorientated.

This mixed method study, whilst acknowledging the high significance of good mentor support to students' clinical learning, questions the practicalities and now established tradition that the mentorship model is often the sole source of support for student nurses on placement. The study explores the possibility of strengthening clinical learning and support by promoting the use of Web 2.0 support groups for student nurses drawn from established peer and academic networks as they make the transition from their academic to their practice learning on placement.

\section{BACKGROUND TO THE STUDY}

The aims of the study sits against the current national usage of Web 2.0 tools by students and the barriers that may exist to the implementation of Web 2.0 tools in education. Both are influential variables on the successful implementation of Web 2.0 tools in practice from one university locality.

\section{Web 2.0 usage and attitude within the student population}


Despite identified pedagogical advantages a two year study of first year students across five UK universities found significant variations in their use of new technologies including Facebook (Jones at al 2009). Most Web 2.0 technologies attract minimal use if driven by the students themselves with the clear exception being the use of social networking sites such as Facebook (Judd and Kennedy 2010). Student use of Web 2.0 tools demonstrated little homogeneity; a commonality was that Facebook increased significantly in traditional university courses once students had started Higher Education (Jones at al 2009)

The impact of this trend can be seen through the beginnings of the migration of students away from institutional email towards social networking tools (Judd and Kennedy 2010.) Judd (2010) found in a study of undergraduate biomedical students use of webmail and social networking between 2005 and 2009 that the use of email had declined and social networking sites had now gained parity with email usage. By 2009 students were more likely to be involved in social networking sites alone than combining this medium with email. Although Judd (2010) does not suggest email is being ignored, his study indicates this medium is being accessed less frequently and concurs with the author's own anecdotal experience that Facebook communication reaches a greater number of students more effectively.

Opportunities to communicate with academics on social networking sites again does not present an homogenous picture as to students' preferences to academics joining them in their online spaces previously reserved for social interaction (Baran 2010, Junco 2012). The application of wikis at Bournemouth University found first year students, typically comfortable with presenting multiple aspects of their lives in an online context, appear 
more concerned with the purpose and quality of the educational use of Web 2.0 tools and the immediate social presence that is afforded (Morley 2012). Students actively criticise social media provided by universities that are inferior to the accessibility and usability of the online tools that they already use. Dabbagh and Kitsantas (2012) believe that institutional learning management systems do not effectively address learner control and personalisation. They do not provide students with enough opportunity to manage their own learning as well as the all important connection to their peers. Certainly as students compare the ease of accessibility and professional interface of social networking sites such as Facebook it is questionable whether a university site could ever match the student experience.

\section{Barriers to using Web 2.0 tools}

Although academics recognise the potential of using online communication tools already popular and established within the student body, barriers exist in translating this awareness into educational practice. Brown (2012) in her study of academic perceptions of Web 2.0 found that Web 1.0, that does not require ongoing student interaction, was well established in academia. The interactive affordances of Web 2.0 seemed to be ignored despite academics desire for student led courses and participation.

Facilitating educational experiences that highlight academics own lack of expertise is potentially problematic and requires a bravery and "letting go" by academics in their interactions with students. Likewise the use of informal or colloquial language on Web 2.0 tools may bring into question the academic rigor of students pooling their experiences online (Wheeler et al 2008, Morley 2012). Although often student nurses formally reflect on 
their own experiences there remains a fear of the absence of academic credibility when this is conducted online.

Some academics are sensitive to the amount of disclosure of themselves that might be revealed through the use of social networking sites with students. Mazer et al (2007) makes the point that self disclosure is already used as a pedagogical tool at university to spike students' interests and even to clarify material by providing real life experiences. They do, however, recommend that Facebook disclosure must be consistent with the teaching style in the classroom and be proceded with caution. Generally it seems more important to student motivation to have immediacy of academic interaction (Mazer et al 2007) and that the academic is aware of how the tool works and is positive about its implementation (Ossiansson 2010, Morley 2012).

Additional and more complex issues of engaging in Web 2.0 tools exist for students undertaking health and social care courses. Breaches of confidentiality are identified in nursing, medical and pharmacist literature where students, communicating about work related matters in an unprofessional way, have compromised their professional and client relationships (Cain et al 2009, MacDonald, Sohn and Ellis 2010, NMC 2011).

Cain et al (2009) recognise that the blurring of the private and public domains within students' lives, through the use of social networking sites such as Facebook, can lead to pharmacy students compromising what would previously have been distinct and separate social and professional identities. Although $90 \%$ of 299 pharmacy students state that caution is paramount with Facebook profiles a third admit that they post information that they would not like accessed by academic staff, future employers or patients. Privacy 
settings on Facebook were not necessarily used and this concurs with a study of 220 graduate doctors where one quarter did not use the privacy options (MacDonald, Sohn and Ellis 2010)

Cain et al (2009) and MacDonald, Sohn and Ellis (2010) point to the imperative of academics providing the health care professionals in their courses with an awareness of issues pertinent to the evolution of professionalism in the digital age. Cain et al (2009) moves beyond isolated netiquette training for students (Morley 2012) and introduces the better rounded construct of e professionalism with the first year pharmacy students in their study.

\section{$\underline{\text { THE STUDY }}$}

During 2009 a new pre registration nursing curriculum at Bournemouth University established the use of wikis within two academic units of the first term of the nursing programme. The evaluative study (Morley 2012) highlighted the potential of Web 2.0 tools within the nursing programme to form a collaborative online space for students to work together on common learning activities irrespective of time and location. Data indicated that $91 \%$ of first year student nurses from a 69 student sample were Facebook users (Morley 2012) and fitted well with the typical profile of student users (Schroeder and Greenbowe 2009)

Following the author's interest in placement support it was routed whether the students' experience of wikis in the curriculum, and Facebook socially, could be harnessed to see whether Web 2.0 tools could provide effective support for first year student nurses on placement. 
On completion of their first term of study student nurses progress into their first clinical placement where their learning is supported by mentors in clinical practice. Exceptional issues generating student concern are usually referred to the students' academic adviser (personal tutor) via email or phone. The level of support students' access from other university services e.g. an internal helpdesk, practice educators and their peer group and informal networks are unknown.

The overall picture indicates a situation whereby first year students are reliant on the day to day management of their clinical learning through their mentor and it is only when difficulties arise that students contact a second party. The question remains as to whether students will accept and use online support effectively in clinical placement and whether the affordances of Web 2.0 tools can be transferred effectively to a situated or work based educational setting.

\section{AIMS AND OBJECTIVES}

This mixed method study proposed to extend the communication support for first year students to their first clinical placement by the use of additional forms of online communication (a wiki, a facebook group, an email group and traditional methods of communicating with academic staff via individual email and /or telephone). The first three tools allowed the additional facility of peer as well as academic support.

1. To identify how often individual participating first year students post a new subject area onto their allocated communication tool during their first clinical placement

2. To identify how often individual participating first year students respond to a post from another member of their elearning group during their first clinical placement 
3. To discover the communication issues and themes that emerge from eight student elearning groups during their first clinical placement

4. To identify factors that influenced individual first year students' access and engagement in differing online communication mechanisms during their first clinical placement

5. To describe pertinent issues relating to the implementation of the project.

For the purposes of the project a "post" $(\mathrm{P})$ is defined as a new subject area introduced onto the communication tool and a "response" (R) as a reply to the post. It is possible for students to introduce a new "post" as part of their "response" to another student and in those circumstances this would be recorded as both a post $(P)$ and a response $(R)$.

The study gained ethical approval from the School of Health and Social Care Research Governance Review at the university where the study was to be undertaken.

\section{SAMPLE AND METHODS}

Two first year seminar groups ( $A$ and B), of approximately 30 and 22 student nurse participants respectively, were selected for the study sample due to the dates that they were entering their first clinical placement. Two groups were selected so the resultant data was better representative of the first year cohort and not based on the idiosyncrasies of one group.

In a first meeting with participants an explanation of the study was presented both verbally and via a participant information sheet.

It was explained to students that the study compromised of two phases: 
1. Monitoring of their use of an online tool to communicate with peers and the author while undertaking their first clinical placement

2. The completion of a post placement questionnaire to ascertain their use and attitude of online communication while on clinical placement

Any inequalities in power relationships which may compromise informed consent were recognised by emphasising to students that they could refuse or withdrawal from the study at any stage. Equally students were free to participate in the communication tools they had been allocated to as and when they wished during the course of the study without any form of coercion from the author.

Participants attended a second meeting to ask face to face questions about the study before they were asked to sign their consent to allow their participation. Students were assured that although students' identity could not be anonymised during communication on placement for the purposes of the publication and presentation of findings students' identity would remain confidential.

During their first academic term at university each student seminar group had been divided into four elearning groups for the purpose of using wikis in two academic units. Student participants for the study, in each of the seminar groups, were placed into the same former student elearning groups that had been used for previous academic collaborative group work online. By using the established membership of the four elearning groups for both A and $B$ the students were allocated to one of the alternative communication tools whilst on their first clinical placement. 
In conjunction with this seminar group A had been taught by the author previously and it was hoped that this previous weekly contact would promote the students' confidence in using online communication tools with a member of university staff they are familiar with. The author had not taught seminar group B and she had met them solely during Fresher's week three months previously.

Communication tools were allocated randomly between the four elearning groups of both group $A$ and $B$ for it was known all students had had previous experience of wikis and a likely experience with Facebook. Technical issues arising from the use of the communication tools could either be fielded through the 24 hour IT services helpline or the author herself. All students were given the option to continue with personal communication to other university support systems and their academic adviser via email if this was preferable or more appropriate for them. The students' use of alternative methods of communication outside the study was hoped to be measured through the post placement questionnaires once the study had been completed.

The choice of how students use their communication tool, the frequency and the issues raised were at the discretion of the group but had to comply with the netiquette training that students had received at the beginning of the academic year.

The outcomes of the netiquette training were reemphasised as well clarifying the established "immediate take down procedure" by the author for removing inappropriate content. This procedure, agreed with students prior to the start of the study, allowed the author to immediately remove inappropriate content such as the identification of patients, clinical settings and staff. 
It was ensured that the elearning groups using Facebook as a communication tool had individually adjusted their privacy settings at group level to the "secret" setting to enable a closed and confidential group for their communication that could only be viewed by named group members (JISC 2011). Likewise the continued use of the established wikis through the university's blackboard website ensured a closed communication group to its members.

\section{DATA COLLECTION}

Quantitative data was collected by the author on a weekly basis from each of the eight elearning groups for the five week period of placement. The number of posts and responses of individual students to each communication tool was measured each week while students' qualitative comments were examined for the type of issue being raised.

Further data was gathered through a self administered questionnaire, completed by participant students after placement, to evaluate the process of using online communication as a support mechanism. The author herself completed a reflective diary during the study to document issues resulting from the implementation of the study.

Once the communication tools have gone "live" in placement the author planned only to respond to posts and questions from students and not to initiate posts herself. This was to ensure posts were student led and reflected student interests and concerns whilst on placement.

It is acknowledged that the lack of face to face contact with the author during the study, the previous exposure to her as a teacher and the former group dynamics of the elearning groups may have an effect on participation in the project (Morley 2012). The ability to 
measure the numbers of students who have accessed their communication tools but left no post or response are not possible to compare across the online communication tools being used.

\section{RESULTS}

\section{Weekly access to students' communication tools}

Students' individual access to their communication tools during their first placement varied significantly. Overall Group A used both the facilities of Facebook and the wiki more than Group B but out of all the mediums Facebook was the one preferred by students in both groups. The groups allocated to either a Facebook or a wiki group used their ability to communicate with peers as well as the author.

The traditional method of contacting academic staff as individual students, through email or telephone, had very low access.

Figure One: Interactivity of the online communication tools

Of the highest participating groups (facebook groups $A$ and $B$ and wiki group $A$ ) discrepancies existed in the number of participating students and the length of time participation occurred during placement.

Table Two: Students' access to online communication tools

\begin{tabular}{|c|c|c|c|}
\hline Student group & $\begin{array}{c}\text { Communication } \\
\text { tool }\end{array}$ & No. of participants & $\begin{array}{c}\text { Duration of use of } \\
\text { tool (weeks) }\end{array}$ \\
\hline A & Wiki & 4 out of 7 & 5 \\
\hline A & Facebook & 4 out of 4 & 4 \\
\hline
\end{tabular}




\begin{tabular}{|c|c|c|c|}
\hline B & Facebook & 3 out of 6 & 2 \\
\hline
\end{tabular}

The content of students' posts and responses remained random throughout the study and varied between specific questions on educational issues to dialogue relating to students' feelings on placement.

"Student: Hi, don't see any chat yet? After 5 days on placement have to say it was not a good experience and not looking forward to this week. I'm basically working as a HCA (health care assistant) and it's worse than working in a nursing home. Cannot see any improvement in the near future. This is going to be a long month.

Author: Hi XXXX. Sorry the placement isn't working out as you hoped. Remember its early days ... and there are quite a few things you can do to improve things. A couple of questions first... what are you doing that you don't think is within your role? Have you had your initial interview with your mentor yet? (-)

Student: Hi XXXX. Today was much better as it was more relaxed being a public holiday. Haven't had my initial interview and my mentor's away for the next week. She's nice btw (by the way) so that is not the problem. I'm seen as a HCA and a very much needed pair of hands. It's ok, just not what I was expecting"

Author: Hi there. Yes, it's interesting how the type of day can make a difference! Have a chat with the person in charge as 2 weeks without an initial interview is quite a long stretch 
without identifying which learning outcomes you are beginning to focus on in your PAT (practice assessment tool). You should have a second mentor if the first is unavailable. Unless you have a focus to your practice learning then the easiest thing to do will be to put you working as a HCA. By the way, I don't think there is anything wrong with this at this particular stage but you really need someone to question you about the care you are doing and why ... keep in touch $(-)$

\section{Students' post placement questionnaire}

The student response rate for their post placement questionnaires differed according to whether the questionnaires were administered to students at university (Group $A(n=12)$ ) or completed on line (Group B ( $n=1)$. The findings were amalgamated together but the low numbers did not allow credible patterns in behaviour or preference for tools to be analysed although qualitative comments brought insight into individual students. This proved a limitation of the study as the lack of student response to the post placement questionnaire meant that the author was unable to isolate the variable of students' use of alternative communication support systems to those used in the study.

\section{Facebook group feedback $(n=3)$}

Students were "used to using Facebook" and it was "easily accessed at any time of day". Students found it helpful as a support tool "I knew someone was there is I needed help" and appreciated "the opportunity to interact with my peers easily about issues on placement". Students appreciated an academic presence.

\section{Email group feedback $(n=7)$}


Some students found the email group difficult to access while for others it was "private, quick and easy". Two comments expressed a preference for Facebook "email seems very formal when I had issues I contacted via text or Facebook". Students appreciated an academic presence.

\section{Wiki group feedback $(n=3)$}

"It was interesting to see what people were up to and how they were getting on" although the lack of comments and participation from other group members was demotivating. Students appreciated an academic presence.

\section{DISCUSSION}

The results of this small mixed method study indicate a preference for the use of Web 2.0 tools, and in particular the social networking site Facebook, as a communication tool with peers and an academic, while on placement.

The affordances of Facebook present a high quality interface that students are familiar with using and allow them to connect with both peers and an academic with ease. This continuing and immediate social connection was welcomed.

"it was helpful to see how everybody was getting on and sharing ideas" (student) Four students, not included in the Facebook groups, attempted to join the Facebook groups or expressed a preference for communication via this method. Participation in an established Facebook group with peers was one reason given for non participation in the group B wiki. 
As the leader of the study the author found setting up a Facebook account, purely for the purposes of the study, straight forward and linked it to her university email account. Due to the affective email alert system via Facebook the author could spend minimal time servicing the Facebook pages and equally required no technical help or assistance in setting up and maintaining her Facebook account. This ease of maintenance, with the ability to access Facebook via the author's smart phone, made this extended student support easy to respond to and access. This correlates with Ossiansson (2010) who noted the time efficiencies and the potential to build egalitarian relationships between academic and student.

The Facebook account contained the minimum of personal information of name, date of birth, place of work and photograph and the privacy setting meant that only members of the Facebook support group could view its existence.

Access to the wiki groups were continued in students' existing academic units where they were originally placed while the email group, that had to be formed through IT, seemed to face numerous problems before it became "live". The author was unsuccessful in establishing alerts for any medium apart from Facebook.

Managing and structuring student comments proved more difficult on Facebook pages than the wiki. Gray, Annabell and Kennedy (2010) analysing the use of Facebook by medical students found, like this study, that some aspects of the layout and functionality of Facebook were not naturally conducive to educational activity. Overall Facebook seemed particular appropriate to informal group work and this potential for placement support was expressed by participating students and in the author's own reflective diary. 
"Do it again, but maybe do from start of the year to make people more aware" (student)

The author's original aims to react only to student posts evolved as the study progressed and she realised the value of connecting to students' posts through the promotion of informal conversations. The colloquial nature of communication seemed very appropriate to the conversations that emerged. The author was careful to monitor the type of questions being asked to see whether to leave them for another student to respond to or whether it would be more appropriate from an academic perspective. Quite often the author would queue in another post on the back of a response in order to keep a conversation going with the student; in this way tools that were being used were self-perpetuating and became a fluid medium.

Attempts to align students' posts more explicitly to educational goals were not met particularly proactively by students who used Facebook and the wiki in group A for either specific questions or as a place to leave reassuring comments for peers. Mazman and Usluel (2010) found that "usefulness" was the most important determining factor to Facebook usage.

Table Three: Comparative uses of online communication tools

\begin{tabular}{|l|l|}
\hline Facebook & $\begin{array}{l}\text { Student participants are members of Facebook and are familiar with access } \\
\text { and usage. Access can be made through varying mediums including smart } \\
\text { phones. The interface is of a high quality and technical help is usually not } \\
\text { required when opening an account. Personal alert systems can be set up to } \\
\text { advise on new input on Facebook pages. Facebook affords students the } \\
\text { opportunity to communicate with peers at a distance with the potential for } \\
\text { academic support. }\end{array}$ \\
$\begin{array}{l}\text { The layout of Facebook pages is set and cannot be changed to suit the } \\
\text { learning task. Student participants must be aware of e professionalism }\end{array}$ \\
\hline
\end{tabular}




\begin{tabular}{|l|l|}
\hline Wiki & dangers inherent in Facebook use and the importance of its management. \\
& $\begin{array}{l}\text { Student participants have previously worked on wikis and are familiar with } \\
\text { access and usage. Access is through the university blackboard intranet site } \\
\text { and can be problematic. The interface is basic and wikis have to be set up for } \\
\text { students via university support systems. Wikis afford students the } \\
\text { opportunity to communicate with peers at a distance with the potential for } \\
\text { academic support. }\end{array}$ \\
$\begin{array}{l}\text { The layout of wikis is conducive to the creation of collaborative documents } \\
\text { and discussion. Students must be aware of netiquette and the membership } \\
\text { of the wiki group. }\end{array}$ \\
\hline Email group & $\begin{array}{l}\text { Student participants rarely work in email groups although email is familiar to } \\
\text { them. Access proved an issue and university support systems were required } \\
\text { to set up email groups. Email can be seen as an old fashioned medium with } \\
\text { which to communicate with peers. }\end{array}$ \\
\hline
\end{tabular}

\section{CONCLUSION AND RECOMMENDATIONS}

Whilst academics struggle on vocational degrees to close the gap that exists between academic and placement learning students are using social networking sites such as Facebook with ease as a multi functional tool across many facets of their lives. Students increasingly access Facebook on smart phones and use their Facebook facilities to access other sites. "Identity is the vehicle that carries our experiences from context to context" (Wenger, 1998: 268) and it would seem that students, through their widespread use of social networking sites, have found a possible facility that allows them to do this.

For nursing students, the Nursing and Midwifery Council (2011), following high profile cases of Facebook abuse, advises caution and suggests students' access recognised professional networking sites such as Linked in as opposed to Facebook. 
The challenge exists as to whether that, with appropriate awareness of the dangers of unprofessional online conduct, social networking sites can be safely managed to connect students in placement with the established support mechanisms of their university and peer groups. Despite recommendations by the NMC (2011) students already discuss their courses, their clinical placements and provide support for peers through their social networking sites. This study therefore concludes with the positive view that it is possible to harness rather than exclude students from potential Web 2.0 mediums and fosters feelings of belongingness online to complement support on placement.

This study highlights the potential for Facebook usage at particular stress points in an academic programme and the potential that a student Facebook support group, with increased user maturity and awareness of their learning needs, could be independently student led.

The study recommends that academics must accept a professional and academic responsibility if deciding to implement Web 2.0 tools within their courses. To ensure success academics should be present in a facilitative capacity to support safe online interaction which promotes trustworthiness, authenticity and credibility of information and the safeguarding of that which is private and confidential (Grover and Stewart 2010). With the blurring between amateur and professional content (Ossiansson 2010) an awareness of e professionalism is essential for all students.

While the use of social networking sites in health and social care education is viewed as a dangerous or subversive activity by universities students are denied the benefits of a high quality and accessible tool, such as Facebook, that encourages collaborative support and 
learning. There is an increased risk that institutions who ignore that Facebook is a fundamental part of students' communication will fail to accept responsibility for the sound development of e.professionalism as part of the curriculum. Thus the professionally naive student is put at increasing risk of professional misconduct and remains isolated from academic guidance and expertise while on placement. 


\section{REFERENCES}

Baran, B., 2010. Colloquium: Facebook as a formal instructional environment. British Journal of Educational Technology, 41 (6), E146-E149.

Benner, P., 1984. From novice to expert. Excellence and power in clinical nursing practice. California: Addison-Wesley Publishing Company.

Brown, S. A., 2012. Seeing web 2.0 in context: A study of academic perceptions. Internet and Higher Education, 15, 50-57.

Cain, J., Scott, D. R., and Akers, P., 2009. Pharmacy students' Facebook activity and opinions regarding accountability and e-professionalism. American Journal of Pharmaceutical Education, 73 (6), 1-6.

Chesser-Smyth, P. A., 2005. The lived experiences of general student nurses on their first clinical placement: A phenomenological study. Nurse Education in Practice, 5, 320327.

Committee, J. I. S., 2012. Facing up to facebook: A guide for FE and HE. Available from: http://www.jisclegal.ac.uk/.../Facing-up-to-Facebook-A-Guide-for-FE-and-HE [Accessed: 04/01/12].

Dabbagh, N., and Kitsantas, A., 2012. Personal learning environments. Social media, and self regulated learning: A natural formula for connecting formal and informal learning. Internet and Higher Education, 15, 3-8.

DeAndrea, D. C., Ellison, N. B., Larose, R., Steinfield, C., and Fiore, A., 2012. 
Serious social media: On the use of social media for improving students' adjustment to college. Internet and Higher Education, 15, 15-23

Dewey, J., 1938. Experience and education. London: Collier-Macmillan Ltd.

Fountain, R., 2005. Wiki pedagogy: About research. Dossiers Technopedagogiques. Available from: http://www.profetic.org:16080/dossiers/article.php3?id_article=974 [Accessed: 06/08/10].

Gray, K., Annabell, L., and Kennedy, G., 2010. Medical students' use of Facebook to support learning: Insights from four case studies. Medical Teacher, 32 (12), 971-976.

Gray, M. A., and Smith, L. N., 2000. The qualities of an effective mentor from the student nurse's perspective: Findings from a longitudinal qualitative study. Journal of Advanced Nursing, 32, 1542-1549.

Grover, A., and Stewart, D., 2010. Defining interactive social media in an educational context. In: Wankel, C. ed. Cutting-edge social media approaches to business education. Charlotte, North Carolina: Information Age Publishing Inc, 7-38.

Jones, C., Ramanau, R., Cross, S., and Healing, G., 2010. Net generation or digital natives: Is there a distinct new generation entering university? Computers and Education, 722732.

Judd, T., 2010. Colloquium. British Journal of Educational Technology, 41 (5), E101-E103.

Judd, T., and Kennedy, G., 2010. A five-year study of on-campus internet use by undergraduate biomedical students. Computers \& Education, 55 (4), 1564-1571. 
Junco, R., 2012. The relationship between frequency of Facebook use, participation in facebook activities, and student engagement. Computers \& Education, 58 (1), 162171.

Levett-Jones, T., and Lathlean, J., 2008. Belongingness: A prerequisite for nursing students' clinical learning. Nurse Education Today, 8, 103-111.

Levett-Jones, T., Lathlean, J., Maguire, J., and Mcmillan, M., 2007. Belongingness: A critique of the concept and implications for nursing education. Nurse Education Today, 27, 210-218.

MacDonald, J., Sohn, S., and Ellis, P., 2010. Privacy, professionalism and Facebook: A dilemma for young doctors. Medical Education, 44 (8), 805-813.

Mazer, J., Murphy, R., and Simonds, C., 2007. Ill see you on "Facebook": The effects of computer-mediated teacher self-disclosure on student motivation, affective learning and classroom climate. Communication Education, 56 (1), 1-17.

Mazman, S., and Usluel, Y., 2010. Modeling educational usage of Facebook. Computers and Education, 55, 444-453.

Mejias, U., 2006. Teaching social software with social software. Innovate Journal of online education, 2 (5). Available from: http://www.innovateonline.info [Accessed: 06/08/10].

Melia, K., 1987. Learning and working. The occupational socialisation of nurses. London: Tavistock Publications. 
Morley, D., 2012. Enhancing networking and proactive learning skills in the first year university experience through the use of wikis. Nurse Education Today, 32 (3), 261266.

Myall, M., Levett-Jones, T., and Lathlean, J., 2007. Mentorship in contemporary practice: The experiences of nursing students and practice mentors. Journal of Clinical Nursing, 17, 1834-1842.

NMC. Social networking sites. 2011 Available from: http://www.nmc-uk.org/Nurses-andmidwives/Advice-by-topic/A/Advice/Social-networking-sites/ [Accessed: 29/12/11].

Ossiansson, E., 2010. Facebook "Friendship" as educational practice. In: Wankel, C. ed. Cutting-edge social media approaches to business education. Charlotte, North Carolina: Information Age Publishing Inc, 117-140.

Schon, D., 1983. The reflective practitioner. How professionals think in action. Aldershot: Ashgate Publishing Limited.

Schroeder, J., and Greenbowe, T., 2009. The chemistry of Facebook: Using social networking to create an online community for the organic chemistry laboratory. Innovate, 5 (4). Available from: http://www.innovateonline.info [Accessed 06/08/10)

Spouse, J., 2001. Bridging theory and practice in the supervisory relationship: A sociocultural perspective. Journal of Advanced Nursing, 33, 512-523.

Taylor, C., 1997. Problem solving in clinical nursing practice. Journal of Advanced Nursing, $26,329-336$. 
Thrysoe, L., Hounsgaard, L., Bonderup Dohn, N., and Wagner, L., 2010. Participating in a community of practice as a prerequisite for becoming a nurse - trajectories as final year nursing students. Nurse Education in Practice, 10, 361-366.

Wenger, E., 1998. Communities of practice. Learning, meaning and identity. New York: Cambridge University Press.

Wheeler, S., Yeomans, P., and Wheeler, D., 2008. The good, the bad and the wiki: Evaluating student-generated content for collaborative learning. British Journal of Educational Technology, 39 (6), 987-995. 